\title{
Notes and activities
}

\section{Third International Symposium on Gastrointestinal Hormones}

This symposium will be held at Cambridge, England, 15-18 September 1980: it will cover the conventional circulating hormones, as well as the locally acting paracrine peptides and the peptidergic innervation. The programme will consist largely of submitted papers with review talks by invited authorities. Deadline for receipt of abstracts 31 March 1980. For details write to: Dr. S. R. Bloom or Dr. J. M. Polak, Royal Postgraduate Medical School, Du Cane Road, London W12 0HS, United Kingdom.

\section{Verdict on Vagotomy}

A one-day symposium on Vagotomy is to be held in Bournemouth on Saturday 29 March 1980, immediately following the joint meeting of the British Society of Gastroenterology and the Association of Surgeons. Members of these Societies have been circulated with details and application forms. Others wishing to come should write to Dr J H Baron, Department of Surgery, Royal Postgraduate Medical School, Hammersmith Hospital, London W12 0HS.

International Symposium on Alcohol and the Gastrointestinal Tract

This symposium will be held at Bischenberg-Strasbourg, France, from 7-8 March 1980. Details from Mlle. Dr. C. Stock, Unité de Recherches de Chirurgie Expérimentale et de Biophysiopathologie Digestive, ZUP Hautepierre, Avenue Molierè, F-67200 Strasbourg, France.

\section{European Congress of Gastrointestinal Endoscopy}

This congress will be held in Hamburg, 13-14 June 1980. Details from Congress Organiser, Congress Project Management, Günther Sachs, Letzter Hasenpfad 61, D-6000 Frankfurt 70.

\section{Books}

Gut Hormones Erlited by S. R. Bloom. (Pp. 664. Illustrated. £17.00.) Churchill Livingstone: Edinburgh, London, and New York. 1979.

First of all, this is a considerable and important book. Despite claims by the publishers and editors of earlier volumes, this is the first book that can be justifiably held to give a comprehensive account of the present state of gut endocrinology. To have achieved this by the publication of papers presented at a symposium is no mean feat, and this suggests that the format of the book was one of the factors governing the choice of speakers and topics. The book is arranged in 17 sections, some of which deal with general principles and techniques, and others with specific hormones. Most sections start with review articles which orientate the uninitiated. Only two sections seem less than successful: the brain/gut relationship is still too elusive to allow clear definition, while the final section on 'Duodenal ulcer' seems to have escaped from a different book altogether. The publishers have done well; the book is clearly laid out, and appears to be letterpress, although closer inspection suggests that new typewriter technology has been used.

Secondly, this is an unusually personal book; the editor's name also appears on 14 of the 103 contributions, and, together with Dr Julia Polak, he has provided a characteristically trenchant 'Gut hormone overview' at the front of the book. I think that this is a fair reflection of the editor's contribution in this field. While many workers have been critical of the vast mass of radioimmunoassay data emanating from the Hammersmith group, and even more so of the putative properties ascribed by Dr Bloom and his colleagues to the various peptides, there is no denying that both the data and the dogma have been a massive stimulus to growth in this field. That Dr Bloom may have been wrong in the past-and may continue to be wrong - is in this sense unimportant; the truth about the gastrointestinal peptides will emerge from the collective research which he has done much to stimulate.

Finally, the message for gastroenterologists is clear, and somewhat dismaying. It has long been regarded as a subspecialty with a comparatively simple scientific substrate. From this book, it is evident that this is no: the case. It is now clear that both the endocrine and the neurophysiological basis of gastroenterology are matters of considerable, and as yet largely unresolved, complexity. For the moment, this is a matter for the scientists, but it must eventually be reflected throughout clinical practice, not only in diagnosis and therapy, but even in the definition and nomenclature of disease and dysfunction. Already overworked, established clinicians are going to have a hard time keeping up. Drs Bloom and Polak conclude their essay with a defiant statement: 'The proper study of alimentary endocrine disorders can at last begin'. A more correct statement might have emerged with the removal of the words 'endocrine disorders' -an endocrinologist can be pardoned for his natural bias-and the substitution of the word 'physiology'.

DAVID WINGATE

Pathways in Surgical Management Michael Hobsley. (Pp. 343. Illustrated. £13.75) Edward Arnold: London. 1979.

The first sentence of the Preface to this interesting new book states 'The arrangement of this book is unorthodox.' It is, however, commendable unorthodoxy, and this applies only to the format of the book. The approach to a wide range of important clinical surgical topics is, on the other hand, much more orthodox than the approach of most other surgical textbooks, in that the text follows the orthodox way in which the vast majority of surgical diagnoses are successfully achieved. Professor Hobsley has simply taken the various ways in which patients present with complaints, symptoms, and signs, and followed the usual logical process in arriving at either a diagnosis, or a therapeutic decision. He has, in fact, dissected out the basic process of the practice of surgery, and produced an excellent book which follows these steps logically and clearly.

There is much of sound practical guidance in the book, and the accent throughout is clearly, and rightly, on clinical decision. A principal feature of the book is the liberal use of flow diagrams, and even those who have a certain allergy to this mode of presentation will find them eminently readable and helpful. Some are simple ones, differentiating one management pathway from another, and others are more comprehensive, summarising the whole approach to a clinical 
problem, such as a palpable abdominal mass, jaundice, a swelling in the thyroid gland, etc. Of course, though much of the content of this book is concerned with gastroenterological topics, it deals with the whole spectrum of disorders which still present to those providing a general surgical service, and it is primarily aimed at undergraduate medical students undergoing the clinical part of their course. However, there is much in this book which would be of real assistance to the postgraduate surgeon in training, and the more senior doctor. It is a very 'browsable' book.

The illustrations are explicit and well chosen, and the style of writing has the delightful merit of reflecting the endearing personal style of the single author, thus giving a feeling of continuity throughout the book.

This is a most refreshing addition to the host of surgical textbooks, and it deserves to be widely used.

I. E. GILLESPIE

Cope's Early Diagnosis of the Acute Abdomen Revised by William Silen. (Pp. 280. Illustrated. £3·50.) Oxford University Press: Oxford. 1979.

Publishers have a difficult task in deciding when to let a book die, particularly a treatise that is as useful and successful as Cope's Early Diagnosis of the Acute Abdomen. This monograph is essentially a personal experience of the subject; the author's involvement comes across throughout the book and the date when that involvement was greatest is immediately apparent. For another author to take over and revise a personal treatise is a near impossible task; such a task can perhaps only be done by a person who knew the author well. Unfortunately, Professor Silen does not have the same style as Zachary Cope, and even Professor Silen's talents are stretched by the task with several passages jarring the reader. The occasional use of 'we' instead of ' $I$ ', the reference to the saving of millions of dollars, and the contrast of Sampson Handley and ultrasound on the same page spoil the image of Zachary Cope's treatise. Added to these criticisms are the poor diagrams and radiographic reproductions, some of which are uninterpretable.

I am afraid that this book should not have been resurrected; it should have died honourably and naturally. As a reference book on the early diagnosis of the acute abdomen by clinical acumen it should have been left on the bookshelves, but in an unrevised form, perhaps alongside a modern text as a contrast.

CHRISTOPHER RUSSELL

Endoscopic Retrograde Cholangio-Pancreatography Edited by $T$. Takemoto and T. Kasugai. (Pp. 328. Illustrated. 178 dutch gilders.) Igaku-shoin: Tokyo. 1979.

The preface correctly states that this is 'the first text in the English language authored enthusiastically by Japanese experts in endoscopy of the pancreas and bile ducts, with special emphasis on endoscopic retrograde cholangio-pancreatography (ERCP)'. Professors Takemoto and Kasugai have assembled 22 distinguished Japanese contributors, including such well-known names as Harada, Kawai, Kobayashi, Ogoshi, $\mathrm{Oi}$, and Tanaka, who have together produced a real monument to Japanese work in this field. There are chapters on historical aspects, equipment and techniques, complications, pancreatic juice and cytology, sphincterotomy, operative and transduodenal choledochoscopy, radiological appearances in the biliary tree and pancreas. Kozu provides new data concerning the correlation between pancreatography and exocrine function studies.

Most contributions are descriptive rather than analytical. The section on technique describes the macroscopic appearances of the duodenum and papilla in detail, but rather lacks practical advice on how to get there. The pull-back technique now used by most Western authorities is ignored; the radiographs virtually all show the 'long route', which has many disadvantages. There are no radiologists among the authors, and little instruction about radiographic technique, which is crucial to maximum diagnostic potential. My main criticism of this book is that it mainly looks backwards, and does not really face up to the main question facing ERCP as it enters its second decade-that of clinical relevance. The chapter on indications is only one page in length, and there is no real discussion about the relative roles of ERCP, percutaneous cholangiography, and new scanning methods such as ultrasonography and computed tomography. This is disappointing when most of the authors are professors in clinical departments. There is some unnecessary overlap between certain chapters, and a hint of competition between authors in developing fields, such as peroral cholangioscopy.

Several other books related to ERCP have appeared recently, with different slants. This book is well produced and departments using the techniques routinely (and attempting to teach them) will certainly wish to add it to their reference libraries.

P. B. COTTON

Techniques of Vagotomy By A. G. Johnson and K. W. Reynolds. (Pp. 85. Illustrated. £5.95.) Edward Arnold: London. 1979.

This short book is an excellent guide to the different vagotomy procedures for the surgeon in training. The text is brief and contains many of the author's ideas and details of technique.

The illustrations are clear and drawn from the surgeon's view.

The three main vagotomy techniques and gastric drainage operations are described; the problems and main points of each procedure are highlighted. Intraoperative tests for completeness of vagotomy are also discussed.

\section{Books received}

The Quality of Life: the Peckham Approach to Human Ethology By Innes H. Pearse. (Pp. 194. Illustrated. £6.50). Scottish Academic Press: Edinburgh. 1979.

Laboratory Investigation of Endocrine Disorders By M. R. Wills, C. W. H. Havard, and P. J. Roylance. (Pp. 96. Figures. £3.25). Butterworths: London. 1979.

Recent Advances in Clinical Immunolology: No. 1. Edited by R. A. Thompson. (pp. 299; illustrated; £11). Churchill Livingstone: Harlow, Essex. 1977.

Non-cirrhotic Portal Fibrosis with Portal Hypertension By A. K. Basu and B. N. Guharay. (Pp. 310. Illustrated. Price not stated). National Academy of Medical Sciences: New Delhi. 